\title{
Improving Early Childhood Prosocial Behavior through Activity Storytelling with Puppets
}

\author{
Ika Tyas Mustika Sari ${ }^{1}$, Hapidin Toha ${ }^{2}$, Yuliani Nurani ${ }^{3}$ \\ Prodi PG-PAUD, Fakultas Ilmu Pendidikan, Pascasarjana Universitas Negeri Jakarta
}

\begin{abstract}
The purpose of this study is to describe the process and learning outcomes through the activities of storytelling with puppets that can improve the prosocial behavior of the children in Kindergarten group A, Global Persada Mandiri School, Bekasi, in the academic year 2017/2018. Research subjects of this action are 14 children aged 4-5 years. This research method is action research which refers to the research of Kemmis MC Taggart which consist of planning, action and observation stage, then reflection. This study consists of 2 cycles, each cycle consisting of 8 meetings. Data analysis technique used in this research is quantitative and qualitative. Quantitative data analysis with statistical descriptions is comparing the results obtained from the pre-action, the first cycle to the second cycle. Qualitative data analysis is done by analyzing data of field record, interview record and documentation record by reducing data, display data and make a conclusion. The results of this study indicate that there is an increase in the behavior of child prosocial through the storytelling activity with puppets, can be proved by the average acquisition of TCP (Level of Development Achievement) in one class at pre-action of 17,7, and increased in the second cycle of 37.5 .
\end{abstract}

Keywords: Prosocial Behavior, storytelling activities, puppets

\begin{abstract}
Abstrak
Tujuan Penelitian Ini adalah untuk mendeskripsikan proses dan hasil pembelajaran melaui kegiatan bercerita dengan wayang yang dapat meningkatkan perilaku prososial anak kelompok A, di TK Global Persada Mandiri School Bekasi, Tahun ajaran 2017/2018. Subjek penelitian tindakan ini berjumlah 14 anak. Metode penelitian ini adalah penelitian tindakan yang mengacu pada penelitian tindakan Kemmis MC Taggart yang terdiri dari tahapan perencanaan, tindakan dan observasi, kemudian refleksi. Penelitian ini terdiri dari 2 siklus, dimana masing-masing siklus terdiri dari 8 kali pertemuan.Teknik analisis data yang digunakan dalam penelitian ini adalah teknik analisis data kuantitatif dan kualitatif. Analisis data kuantitatif dengan deskripsi statistik yaitu membandingkan hasil yang diperoleh dari pra tindakan, siklus pertama hingga siklus kedua. Analisis data kualitatif dilakukan dengan menganalisis data hasil catatan lapangan, wawancara dan dokumentasi dengan mereduksi data, display data dan membuat kesimpulan. Hasil penelitian ini menunjukkan adanya adanya peningkatan perilaku prososial anak melalui kegiatan bercerita dengan wayang, dapat dibuktikan dengan perolehan rata-rata TCP (Tingkat Capaian Perkembangan) dalam satu kelas, yaitu pada saat kegiatan pra tindakan sebesar 17,7, kemudian saat sikulus terakhir mengalami peningkatan sebesar 37,5
\end{abstract}

Kata Kunci : Perilaku prososial, kegiatan bercerita, wayang.

@ Jurnal Obsesi Prodi PG-PAUD FIP UPTT 2018

$\triangle$ Corresponding author:

Address : Jakarta, Indonesia

ISSN 2356-1327 (Media Cetak)

Email : d.tyasmustikasari@gmail.com

ISSN 2549-8959 (Media Online) 


\section{PENDAHULUAN}

Perilaku prososial perlu dikembangkan terutama dilingkungan lembaga PAUD, karena sekolah merupakan ruang lingkup dimana seorang anak secara formal belajar tentang lingkungan sosial mereka. Sekolah merupakan lembaga awal yang dapat membantu anak dalam bersikap prososial dan sekolah juga merupakan salah satu wadah yang memberikan peranan penting dalam perkembangan perilaku prososial bagi anak. Selain itu tugas pendidik atau guru yaitu membimbing anak didiknya agar berperilaku dan membiasakan diri untuk berperilaku yang prososial, bertutur kata yang baik dan tidak saling bertengkar dan berolok-olok dalam pergaulan sehari-hari, saling menyayangi, saling berkerjasama dan berbagi dengan teman (Aisyah,2012: 122)

Lingkungan sekolah, termasuk temanteman di sekitar anak juga mempengaruhi pembentukan perilaku prososial mereka. Perilaku dan kemampuan prososial yaitu kemampuan dan keinginan untuk menghibur, membantu, membela dan berteman dengan teman sebayanya (Patersen dan Wittmer, 2015:155).

Selain guru teman sebaya juga merupakan salah satu tempat dimana anak belajar tentang perilaku prososial yang baik. Prosocial is sharing something with another person, showing wilingness to cooperate, helping and comforting someone in distress are pro-social behaviours that refer to voluntary behaviour intended to benefit another person ( Ulutas dan Aksoy 2009:39). Pendapat tersebut dapat diartikan bahwa perilaku prososial adalah berbagi sesuatu dengan orang lain, mau bekerjasama, membantu dan menghibur seseorang ketika merasa kesusahan, perilaku prososial juga mengacu pada keadaan sukarela yang dapat menguntungkan orang lain.

Hal tersebut di atas sejalan dengan penelitian yang dilakukan oleh (Serly dkk., 2014:1-5), yang berjudul "Studi tentang Perilaku Prososial dan Penanganan Konselor terhadap Perilaku Unsosial pada Anak Usia Dini Di Tk Islam Al-Kalam Surabaya (2014)". Dalam penelitian ini yang menjadi subyek penelitian adalah kepala sekolah, konselor, guru kelas TK A dan seluruh anak TK A di TK Islam Al Kalam. Penelitian ini bertujuan untuk meningkatkan perilaku prososial. Hasil dari penelitian ini menemukan bahwa memberikan penghargaan berupa pujian kepada anak-anak serta memberikan model perilaku yang baik bagi anak-anak dapat meningkatkan perilaku prososial pada diri anak. Fakta di lapangan setelah dilakukan observasi awal pada anak kelompok A di TK Global Persada Mandiri School Bekasi, disimpulkan tingkat perilaku prososial anak belum tercapai secara maksimal. Dari hasil pengamatan awal menunjukkan 11 dari 14 anak $(78,5 \%)$ di kelas kelompok A belum dapat membantu sesama, berbagi dan bekerjasama dengan teman. Anakanak lebih senang bermain sendiri, saling memukul apabila mainan yang mereka bawa dipinjam teman dan apabila melihat teman yang memerlukan bantuan, seperti saat melihat temannya jatuh, mereka cenderung tidak perduli bahkan beberapa anak mentertawakan.

Solusi yang coba ditawarkan adalah dengan memberikan kegiatan bercerita dengan wayang untuk meningkatkan perilaku prososial anak. Sudah banyak diketahui bahwa, dalam pertunjukan Menurut Purwadi (2007;2) wayang selalu berisi nasihat, tidak hanya untuk mengajak beribadah, pendidikan, pengatahuan dan juga hiburan, akan tetapi juga dibarengi dengan nyanyian, lukisan, estetis dan petuah religius yang sangat indah sehingga dapat mengantarkan orang untuk terus mendengarkannnya. Sebab tokoh dalam cerita merupakan gambaran tokoh karakter manusia secara khas sehingga banyak orang tertarik dengan penampilan tokoh yang ada di dalamnya. Media wayang sekarang sudah banyak digunakan dalam pendidikan, sebagai bahan yang digunakan untuk menyampaikan pesan-pesan moral bagi peserta didik

Sejalan dengan pendapat di atas, penelitian yang dilakukan oleh Remer \& Tzuriel (2015, h. 356-365) tentang efektivitas penggunaan wayang sebagai media untuk anak, menunjukkan efektivitas penggunaan wayang pada anak memiliki potensi untuk menciptakan komunikasi, meningkatkan keterlibatan dan mengubah sikap anak. Oleh sebab guru yang memegang peranan penting di dalam kelas harus dapat mengajarkan kepada anak untuk dapat berperilaku prosossial dengan orang lain. Menurut Sudjana,(2013) dalam Fauziddin (2017: 43-44) Mengajar adalah cara yang digunakan guru dalam mengadakan 
hubungan dengan siswa pada saat berlangsungnya pengajaran. Sehingga metode mengajar sebagai alat untuk menciptakan proses mengajar dan belajar haruslah sesuai. Maka dari itu peneliti tertarik untuk melakukan penelitian tentang peningkatam perilaku prososial melalui metode bercerita dengan wayang

\section{METODE}

Penelitian ini dilakukan pada anak kelompok A, di TK Global Persada Mandiri School Bekasi, pada tahun ajaran 2017/2018. Penelitian ini menggunakan metode penelitian tindakan yang mengacu pada tahapan penelitian tindakan Kemmis MC Taggart yang meliputi tahapan perencanaan, tindakan dan observasi serta refleksi. Penelitian ini dinyatakan berhasil apabila $71 \%$ dari seluruh jumlah anak mencapai kriteria ketuntasan minimal (Mills 2003) atau dapat dikatakan 10 dari 14 anak mencapai Tingkat Capaian Perkembangan (TCP) minimal yang ditentukan bersama dengan kolaborator yaitu $70 \%$ dari TCP maksimal.

$$
\begin{aligned}
\text { TCP Max } & =\sum \text { butir X } \sum \text { kategori } \\
\text { TCP Max } & =\sum \text { butir X } \sum \text { kategori } \\
& =12 \text { X } 4 \\
& =48 \\
\text { TCP Min } & =70 \% \text { X TCP Max } \\
& =70 \% \times 48 \\
& =34
\end{aligned}
$$

Teknik pengumpulan data yang digunakan dalam penelitian ini adalah observasi, wawancara dan dokumentasi. Data tentang keterkaitan antara perencanaan dan pelaksanaan pembelajaran diketahui berdasarkan Rencana Kegiatan Harian (RKH) dan lembar instrumen perilaku prososial yaitu membantu, berbagi dan bekerjasama.

\section{HASIL DAN PEMBAHASAN}

Pada siklus I, anak-anak diberikan tindakan berupa kegiatan bercerita dengan wayang untuk meningkatkan perilaku prososial. Kegiatan bercerita yang dilaksanakan yaitu menceritakan tentang kejadian atau peristiwa yang dekat dengan anak, misalnya bercerita mengenai perilaku membantu teman, berbagi makanan, berbagi mainan, berbagi cerita dengan teman dan saling bekerjasama. Moeslichatoen (2004:157) mengatakan bahwa metode bercerita (storytelling) merupakan salah satu pemberian pengalaman belajar bagi anak usia dini secara lisan, sehingga kegiatan bercerita

(storytelling) dapat memberikan pengalaman belajar anak untuk berlatih mendengarkan informasi tentang pengetahuan, nilai dan sikap untuk dihayati dan diterapkandalam kehidupan seharihari. Selain dapat memberikan pengalaman yang baru dengan cerita-cerita yang menarik untuk anak, bercerita juga menambah wawasan dan juga pengalaman anak, karena dalam sebuah cerita pasti ada pesan-pesan moral yang disampaikan yang nantinya bisa diterapkan dalam kehidupan anak.

Pelaksanaan siklus I dilaksanakan dalam 8 kali pertemuan. Peneliti menggambarkan secara keseluruhan bagaimana proses dan hasil penelitian dari pertemuan ke-1 hingga ke-8. Hasil Pengamatan peneliti dan kolaborator terhadap perilaku prososial anak setelah melakukan kegiatan bercerita dengan wayang selama 8 kai pertemuan

\begin{tabular}{|c|c|c|c|}
\hline \multirow[t]{2}{*}{ No } & \multirow[t]{2}{*}{ Subyek } & PraTindakan & Siklus I \\
\hline & & TCP & TCP \\
\hline 1 & ALN & 22 & 31.0 \\
\hline 2 & $\mathrm{AZH}$ & 17 & 27.6 \\
\hline 3 & $\mathrm{AS}$ & 18 & 26.1 \\
\hline 4 & ANS & 24 & 30.9 \\
\hline 5 & EL & 12 & 23.1 \\
\hline 6 & FLK & 16 & 26.0 \\
\hline 7 & $\mathrm{JN}$ & 16 & 27.3 \\
\hline 8 & $\mathrm{KH}$ & 23 & 34 \\
\hline 9 & NL & 16 & 27.3 \\
\hline 10 & $\mathrm{VN}$ & 14 & 26.9 \\
\hline 11 & RHN & 19 & 27.6 \\
\hline 12 & SF & 18 & 29.1 \\
\hline 13 & SHN & 17 & 27.9 \\
\hline 14 & SYK & 19 & 29.3 \\
\hline Rata & ta kelas & 17.9 & 28.1 \\
\hline
\end{tabular}
berdasarkan lembar observasi instrumen perilaku prososial anak disajikan dalam tabel dan grafik sebagai berikut:

Tabel 1 Perilaku Prososial pada Siklus I Anak Kelompok A, di TK Global Persada Mandiri School 
Grafik 1. Perilaku Prososial pada Siklus I Anak Kelompok A, di TK Global Persada Mandiri School Tahun 2017-2018.

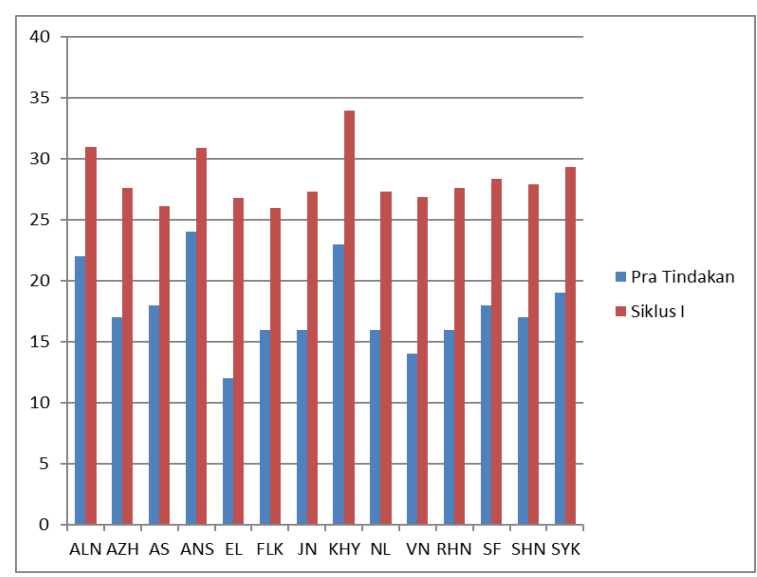

Berdasarkan data di atas maka diketahui bahwa skor maksimum yang diperoleh anak pada siklus I sebesar 34 sedangkan skor minimum sebesar 23.1, dengan rata-rata kelas sebesar 28.2. Hasil asesmen menunjukkan peningkatan perilaku prososial meskipun belum mencapai target yang disepakati oleh peneliti dan kolaborator yaitu 34 .

Kriteria keberhasilan dalam penelitian ini adalah 71\% (Mills, 2003) artinya dinyatakan berhasil bila mencapai tingkat capaian perkembangan minimal yang ditentukan oleh peneliti dan kolaborator yaitu sebesar $70 \%$. Dengan kata lain, penelitian tindakan dinyatakan berhasil jika sebanyak 10 anak mencapai minimal sebesar 34. Hasil dari siklus I menunjukkan bahwa hampir semua anak masih memiliki skor di bawah TCP minimal yang ditentukan. Penelitian tindakan ini belum berhasil dan akan dilanjutkan ke siklus II dengan beberapa pebaikan berdasarkan pada siklus I.

Dari hasil pengamatan, catatan observasi, catatan lapangan dan dokumentasi pelaksanaan tindakan siklus I, maka peneliti dan kolaborator melakukan refleksi untuk mencari hambatan-hambatan apa yang ditemui guru di siklus I yaitu:

1) Beberapa anak masih sulit untuk dikendalikan saat kegiatan bercerita berlangsung, karena ingin maju kedepan melihat dan berebutan memegang wayang.
2) Terkadang perhatian anak terganggu karena saat bercerita, dalam saat bersamaan anak juga mengungkapkan pendapatnya.

3) Anak masih memerlukan bimbingan dan motivasi untuk percaya diri saat melakukan tanya jawab, sehingga terkadang untuk memancing anak lebih percaya diri dan mau menjawab pertanyaan guru memberikan hadiah bagi anak-anak yang bisa menjawab pertanyaan.

4) Anak memerlukan duduk di posisi yang tepat saat kegiatan bercerita

5) Suara guru terkadang tidak terdengar saat improvisasi suara,

Peneliti bersama kolaborator berusaha untuk mencari solusi yang tepat untuk mengurangi hambatan-hambatan diatas dengan cara yang terbaik untuk anak-anak. Solusi yang akan dilakukan pada siklus II yaitu:

1) Pada siklus I, kegiatan bercerita tidak melibatkan anak dalam mempersiapkan panggung dan wayang, sehingga ketika bercerita anak berebut untuk memegang wayang, di siklus II anak dilibatkan dalam mempersiapkan kegiatan bercerita dan diperbolehkan bergiliran memainkan wayang

2) Saat bercerita di siklus I, anak-anak masih kurang tertib karena saat bercerita anak juga menceritakan pengalaman mereka, di siklus II anak yang ingin berbicara harus mengangkat tangannya terlebih dahulu baru mereka boleh mengutarakan pendapat mereka.

3) Anak masih terlihat malu menjawab saat ditanya oleh guru, sehingga di siklus II guru akan memberikan hadiah berupa stiker bagi anak yang bisa menjawab pertanyaan yang diberikan guru

4) Anak diberikan kebebasan untuk memilih tempat duduk mereka saat siklus I dan ternyata itu membuat mereka asyik mengobrol sendiri, akhirnya saat siklus II, posisi anak dirubah sesuai dengan urutan yang 
disusun guru, agar anak-anak fokus mendengarkan cerita.

5) Suara guru terkadang tidak terdengar dengan jelas, sehingga pada siklus II guru akan menggunakan mikrofon untuk menarik perhatian anak.

Pelaksanaan siklus II terdiri dari 8 kali pertemuan berjalan dengan lancar sesuai rencana. Guru terlihat selalu memotivasi anak-anak saat kegiatan bercerita dan melakukan improvisasi yang membuat anak-anak lebih tertarik mendengarkan cerita. Dari ttindakan dan hasil observasi pada siklus II, peneliti dan kolaborator melakukan pengamatan terhadap perilaku prososial anak menggunakan lembar instrumen. Hasil analisis data kuantitatif dalam perilaku prososial anak yang disajikan dalam bentuk tabel dan grafik berikut:

Tabel 2 Perilaku Prososial pada Siklus II Anak Kelompok A di TK Global Persada Mandiri

\begin{tabular}{|l|l|l|l|l|}
\hline \multirow{2}{*}{$\begin{array}{l}\mathrm{N} \\
\text { o. }\end{array}$} & \multirow{2}{*}{ Subyek } & \multicolumn{3}{|c|}{ Skor } \\
\cline { 3 - 5 } & & $\begin{array}{c}\text { Pra- } \\
\text { tindakan }\end{array}$ & Siklus I & Siklus II \\
\hline 1 & ALN & 22 & 31 & 41,5 \\
\hline 2 & AZH & 17 & 27,6 & 37,9 \\
\hline 3 & AS & 18 & 26,1 & 39,5 \\
\hline 4 & ANS & 24 & 30,9 & 42,1 \\
\hline 5 & EL & 12 & 26,8 & 30,1 \\
\hline 6 & FLK & 16 & 26 & 30,8 \\
\hline 7 & JN & 16 & 27,3 & 39,0 \\
\hline 8 & KH & 23 & 34 & 43,9 \\
\hline 9 & NL & 16 & 27,3 & 39,3 \\
\hline 10 & VN & 14 & 26,9 & 30,8 \\
\hline 11 & RHN & 16 & 27,6 & 35,3 \\
\hline 12 & SF & 18 & 28,4 & 39,8 \\
\hline 13 & SHN & 17 & 27,9 & 39,0 \\
\hline 14 & SYK & 19 & 29,3 & 37,1 \\
\hline \multicolumn{2}{|c|}{$\begin{array}{l}\text { Rata-rata } \\
\text { kelas }\end{array}$} & 17,7 & 28,2 & 37,5 \\
\hline \multicolumn{5}{|c|}{}
\end{tabular}

Grafik 2 Perilaku prososial pada siklus II Anak Kelompok A di TK Global Persada Mandiri School

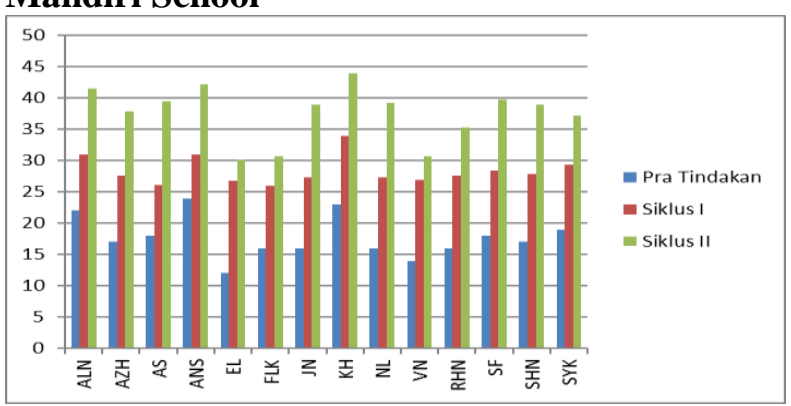

Berdasarkan data di atas, diketahui skor maksimum yang diperoleh anak pada siklus II sebesar 43,9 sedangkan skor minimum sebesar 30,1, dengan rata-rata kelas sebesar 37,2. Hasil asessmen menunjukkan bahwa nilai anak meningkat dari pra tindakan diperoleh nilai rata-rata 17,7 setelah tindakan siklus I mengalami peningkatan 10,5 dengan rata-rata kelas menjadi 28,2, dan setelah dilanjutkan siklus II mengalami peningkatan lagi sebesar 9,3 dengan nilai rata-rata kelas sebesar 37,5. Sehingga siklus II ini telah mencapai target, karena nilai minimum yang telah disepakati peneliti dan kolaborator adalah 33,6.

\section{PEMBAHASAN}

\section{Proses penggunaan wayang dapat meningkatkan perilaku prosossial anak.}

Proses bercerita guru menggunakan wayang dengan berbagai macam tokoh supaya dapat menarik minat anak, guru juga harus melatih suara agar tidak hanya memiliki satu karakter suara tetapi bisa dengan berbagai macam karakter suara yang bisa menarik perhatian anak. Hal tersebut sejalan dengan penelitian yang dilakukan oleh Arti, dkk (2012:3), yang juga mengatakan bahwa ketentuanketentuan dalam melaksanakan kegiatan bercerita dengan menggunakan boneka wayang diantaranya yaitu guru hafal isi cerita serta menggunakan skenario cerita. Melatih suara agar dapat memiliki beragam karakter suara yang dibutuhkan. Menggunakan boneka wayang yang menarik dan sesuai dengan dunia anak serta mudah dimainkan oleh guru atau anak-anak. Bisa menggunakan satu, dua, tiga boneka wayang dengan jumlah maksimal boneka yang digunakan sebanyak 5 buah dengan bentuk yang berlainan. Selain itu alur cerita yang digunakan dibuat oleh peneliti dan kolaborator sesuai dengan aspek perilaku prososial yang ingin ditingkatkan sehingga cerita tidak terlalu panjang. Hal tersebut sejalan dengan penelitian dari Handayani, dkk (2016), yang mengatakan bahwa saat melakukan kegiatan bercerita haruslah 
menggunakan cerita pendek, agar anak bisa lebih mudah untuk mengingat dan serta memahami isi dari cerita tersebut. Memberikan dorongan pada anak untuk berani menjawab pertanyaan guru untuk mengingat apa yang telah didengarnya, dengan cara memeperlihatkan kembali media wayang yang digunakan saat bercerita.

\section{Hasil bercerita dengan wayang dapat meningkatkan perilaku prososial anak}

Berdasarkan data di lapangan melalui kegiatan bercerita dengan wayang dapat meningkatkan perilaku prososial anak. Proses siklus I, berjalan dengan baik meskipun ada beberapa kendala yang terjadi seperti anak terlihat mulai jenuh ketika guru bercerita terlalu lama, anak kurang antusias ketika wayang yang digunakan selalu sama saat bercerita, suara guru kalah dengan suara anak-anak, beberapa anak masih bercerita sendiri, beberapa hal tersebut membuat tindakan siklus I belum dapat mencapai Tingkat Capaian

Perkembangan pada anak kelompok A, sehingga guru merencanakan siklus II dengan perbaikan dari berbagai kendala yang ditemui saat melakukan siklus I. Saat siklus II, guru mulai membuat banyak tokoh wayang, sehingga saat bercerita wayang yang digunakan selalu berbeda, hal ini ternyata membuat anak antusias mendengarkan cerita. Guru mencoba membuat sendiri alur cerita yang fokus terhadap aspek perilaku prososial untuk digunakan saat bercerita dengan wayang, karena saat menggunakan cerita dari buku seperti siklus I, ceritanya terlalu panjang dan anak terlihat mulai bosan. Guru mulai menggunakan mikrofon saat bercerita sehingga anak mendengar dengan jelas cerita yang disampaikan guru dan untuk menghindari anak saling bercerita sendiri guru mencoba memilih tempat duduk untuk anak-anak, yaitu dengan posisi anak yang aktif di kelas duduk dekat dengan anak yang pendiam.

\section{UCAPAN TERIMA KASIH}

Terimakasih penulis ucapkan kepada tim editor E-Journal Obsesi yang sudah memberikan kesempatan sehingga jurnal ini siap untuk diterbitkan. Kepada Dr. Hapidin, M.Pd dan Dr Yuliani Nurani, M.Pd yang bersedia membimbing dengan sabar memberikan motivasi, bimbingan serta kritik dan saran dalam penyusunan Jurnal ini. Kepada reviewer yang sudah mau meluangkan waktunya untuk memberikan banyak masukan sehingga jurnal ini lebih sempurna

\section{SIMPULAN}

Berdasarkan hasil analisis dan pembahasan pada penelitian dengan judul Peningkatan Perilaku Prososial melalui Kegiatan Bercerita dengan Media Wayang maka dapat disimpulkan bahwa sebagai berikut: (1) Pelaksanaan kegiatan bercerita dengan wayang dapat meningkatkan perilaku prososial anak kelompok A di TK Global Persada Mandiri. (2) Melalui kegiatan bercerita dengan wayang dapat meningkatkan perilaku prososial anak kelompok A di TK Global Persada Mandiri School. Peningkatan tersebut dapat dilihat pada skor pra tindakan diperoleh nilai ratarata sebesar 17,7 atau $36,9 \%$, kemudian siklus I mengalami peningkatan 28,2 atau $58,8 \%$ dan dilanjutkan siklus II mengalami peningkatan lagi dengan rata-rata kelas 37,2 atau $78 \%$.

\section{DAFTAR PUSTAKA}

Aisah, Iceu, "Strategi Penumbuhan Perilaku Prososial Anak Usia Dini Melalui Metode Bercerita (Studi Kasus Di Pendididkan Anak Usia Dini (Paud) Matahari Rw X1v Kelurahan Citeureup Kecamatan Cimahi Utara Kota Cimahi”, (Jurnal Empowerment Volume 1, Nomor 2, 2012)

Fauziddin ,Moh. 2017. Upaya Peningkatan Kemampuan Bahasa Anak Usia 4-5 Tahun melalui Kegiatan Menceritakan Kembali Isi Cerita di Kelompok Bermain Aisyiyah Gobah Kecamatan Tambang. Jurnal Obsesi Volume 1 Nomor 1 Tahun 2017 
Handayani, Tri Utami Ngesti. "Upaya Peningkatan Kepercayaan Diri dengan Metode Bercerita Menggunakan Wayang Kardus Pada Anak. Jurnal Ilmiah PG-Paud IKIP Veteran Vol 2 (2), 2014.

Moeslichatoen R, Metode Pengajaran di Taman Kanak-kanak.. Jakarta: Rineka Cipta, 2004.

Petersen,Sandra H. dan Donna S. Wittmer,. "Kurikulum Pendidikan Anak Usia Dini Berbasis Pendekatan Antarpersonal (A Relationship-Based Approach". Jakarta: Prenadamedia Group. 2015.

Purwadi. "Wayang Purwa." Yogyakarta: Panji Pustaka Yogyakarta, 2007

Remer, Ronit \& David Tzuriel, "I Teach Better with the Puppet" Use of Puppet as a Mediating Tool in Kindergarten Education an Evaluation," (School of Education, Bar-Ilan University Ramat-Gan, Israel 2015).

Sari, Arti Syntha Yulia, dkk. Penggunaan Alat Peraga Boneka Wayang Untuk Meningkatkan Kemampuan Bercerita Pada Anak Kelompok B TK Aisyiyah 56 Baron. 2012.

Ulutas, Ilkay \& Ayase Aksoy. "Learning with play: How play activities program improve pro-social behaviour of six year old children?." (Humanity \&Social Sciences Journal, 2009). 